\title{
Development and research of tillage operating device with polymeric materials
}

\author{
Igor Bozhko ${ }^{1, *}$, Galina Parkhomenko ${ }^{1}$, Sergey Kambulov ${ }^{1}$, Andrey Boyko ${ }^{2}$, Vladimir \\ Kolodkin ${ }^{2}$, Magomed Magomedov ${ }^{2}$, and Dmitriy Rudoy ${ }^{2}$ \\ ${ }^{1}$ State Scientific Establishment “Agricultural Research Center "Donskoy", 14, Lenin st., 347740, \\ Zernograd, Russia \\ ${ }^{2}$ Don State Technical University, 1, Gagarin sq., 344003, Rostov on Don, Russia
}

\begin{abstract}
Polymeric materials are advised to be used in the construction of operating devices for energy-saving soil cultivation. Purpose of work is to develop the design of new operating devices with polymer materials. Development of the design of new operating devices with polymeric materials is carried out by replacing part of the metal parts with ultra-high molecular polyethylene of low density. New operating devices carry out several technological operations in one pass. The design of the new operating device contains a rack with a chisel for deep tillage. The front of the rack is equipped with removable plowshare blades. Clod crusher with a possibility of movement and thrust plate are located at the chisel. In the upper part of the rack the ripper for surface tillage is mounted with the possibility of replacing. Ultra-high molecular polyethylene of low-density was installed on the chisel and clod crusher of the tillage operating device, the thrust plate and the ripper for surface tillage are made entirely of polymeric material. Decrease to $18.28 \%$ of draught resistance of the operating device with polymeric materials was established.
\end{abstract}

\section{Introduction}

Currently, in engineering polymeric materials are becoming more widespread. Engineering is one of the largest consumers of metal. Thanks to the introduction of advanced polymeric materials, the metal consumption of machines is reduced. Reducing the mass of the structure will compensate the increase in production costs for new polymeric materials.

The low weight and low resistance of the processed medium to polymeric materials allows them to be used in the design of operating devices for energy-saving soil cultivation. In addition, decrease in the mass of the operating devices of agricultural machines has a positive effect on the conservation of soil fertility, since the overconsolidation of the formation and the likelihood of the manifestation of the associated negative consequences are reduced. There is unlimited adaptation of the properties of polymers based on composite materials that can be used in many engineering structures.

\footnotetext{
*Corresponding author i.v.bozhko@mail.ru
} 
As a result of studying the mechanical behavior of the geometric model of the rack and modeling its material, the authors of [1] proved the economic feasibility of producing elements of the soil cultivating operating device from polymer based on composite materials with the appropriate selection of the volume ratio of fibers in each layer as less expensive than using traditional materials - steels. Field studies have shown the durability of the elements of the tillage operating device, made of polymer based on composite materials, under difficult working conditions compared to those made of alloy steel.

The surface of the operating device of polymeric materials is less susceptible to soil adherence than steel. The use of ultra-high molecular weight polyethylene can solve the problems of adherence, wear and corrosion on plows, cultivators and other tillage machines. Due to their low density and high endurance, the operating devices of ultra-high molecular polyethylene can compete with ones made of low-strength structural steels. Purpose of work is to develop the design of new operating devices with polymeric materials.

\section{Materials and methods}

The design development of new operating devices with polymeric materials is carried out by replacing some of the metal parts with ultra-high molecular polyethylene - thermoplastic of amorphous-crystalline structure, consisting of chain and branched molecules. Replacement of structural parts of the operating device from metal to polymeric material must be made on the basis of analysis of its characteristics, which include strength properties.

The tensile strength of polymeric materials is determined by numerically simulating the interaction of the medium with viscoelastic isotropic thermoplastic taking into account the elasticity and structural strength of its molecules, consisting of linear chains with no polar groups (ester, amide, hydroxyl), the length of which determines the wear resistance, regularized by fractional elastic gradient of tensile and shearing strain [2].

Based on the phase field method, the fracture process of brittle and viscoelastic materials subjected to deformations is described. The main feature of this theory is that the free energy of viscoelastic materials is not completely entropic in nature, and bond strains in the molecular chain also have an effect. This is part of the free energy, which is the driving force behind crack growth, damage and fracture [3].

The equation for the quantitative estimation of the free energy of the polymeric chain takes into account not only the influence of entropy, but also changes in the internal energy during bond deformation in the molecular chain due to diffusion processes [4].

Model has been proposed for assessing the effect of deformation on the destruction of polymers based on two components: model of statistical mechanics of polymeric chains, which explains the increase in energy due to the deformation of molecular bonds, and criterion for breaking chain based on the energy of bond deformation when critical value is reached $[5,6]$. To determine the tensile strength of polymeric materials, data on the relaxation time are required. It is known that approximate determination of the relaxation time based on the approximation of the experimental data of similar materials is often incorrect.

It is almost impossible to find reliable solution using approximation. It is necessary to reconstruct the time-dependent properties obtained by step load [7].

The experimental determination of the relaxation time of linear viscoelastic materials requires the application of ideal step load to the material. However, this cannot be often achieved.

Methods lose their effectiveness if the experimental data collection system does not provide a sufficiently low sampling frequency. 
Several comparative studies of the methods were carried out, all of which were based on simulated reaction of a hypothetical material, but not on real experimental data [8].

According to the obtained data, the viscoelastic state of plastics is calculated, the results of which are used in subsequent modeling of the interaction of the structure with the processed medium (soil).

Several methods for modeling viscoelastic materials have been proposed in the literature, including widely used rheological models.

These models are characterized by certain parameters ("time constants") that determine the relaxation period of the material. These parameters are mainly obtained from stress relaxation experiments using curve fitting methods.

Approach based on the methods of Fisher information geometry and Kullback - Leibler divergence [9] is proposed for the most accurate determination of time constants.

Basing on the research on the modeling results using [2-11], the design of new tillage operating device with polymeric materials was developed.

\section{Research results}

New operating devices carry out several technological operations in one pass, with the principle of action, according to nature-like technologies based on the formation destruction along the natural lines of soil sliding along the path of least resistance $[12,13]$.

The polymeric material must be mounted in local wear zones and areas of increased friction of the tillage operating device. The design of the new operating device contains rack with the chisel for deep tillage. The front of the rack is equipped with removable share blades. Clod crusher with possibility of movement and thrust plate are located on the chisel. In the upper part of the rack ripper for surface tillage is mounted with the possibility of replacing.

At the initial stage of research, the method of mounting polymeric material by means of the mechanical joint was used.

Ultra-high molecular polyethylene of low-density was installed on the chisel and clod crusher of the tillage operating device; the thrust plate and the ripper for surface tillage are made entirely of polymeric material (Figure 1).

Experimental setup has been developed to create real technological process of functioning under conditions of semi-blocked cutting with additional operating device ahead that prepares soil layer for the test one. 


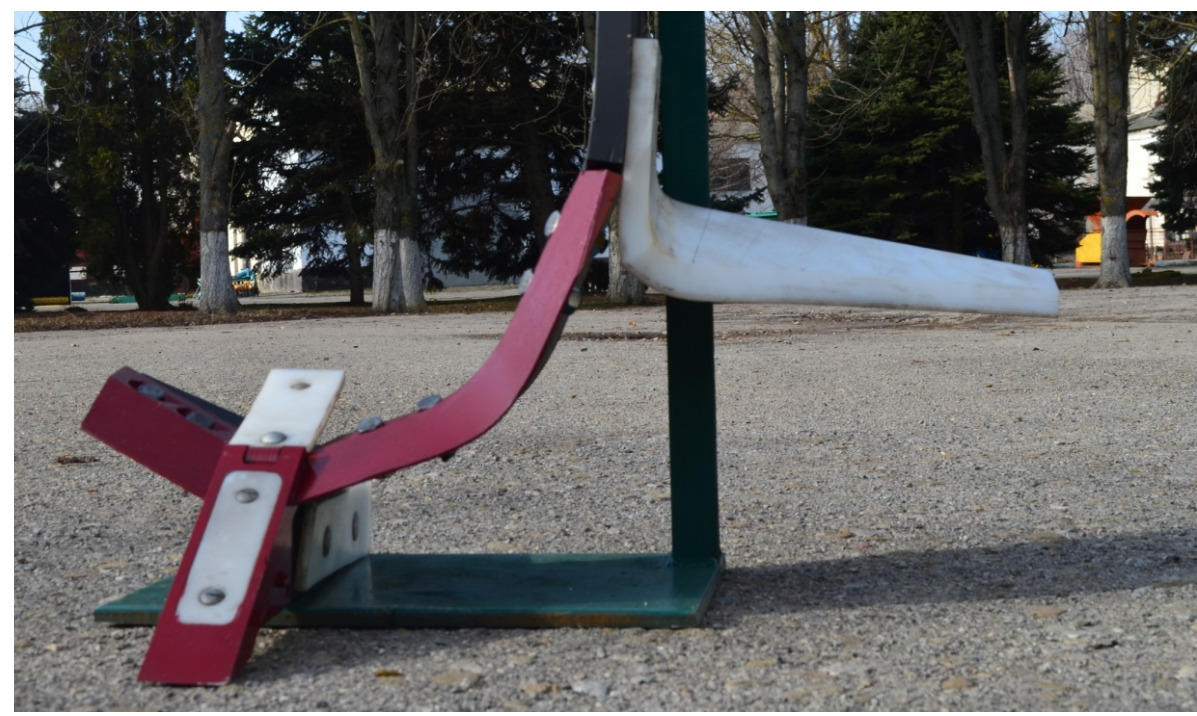

Fig. 1. Tillage operating device with polymeric materials.

The results of the study are presented in Table 1.

Table 1. The results of the study of agrotechnical indicators of new operating device with polymeric materials operating on various backgrounds.

\begin{tabular}{|l|c|c|c|}
\hline \multirow{2}{*}{ Name of indicator } & \multicolumn{3}{|c|}{ Metric value for background } \\
\cline { 2 - 4 } & $\begin{array}{c}\text { Stubble of winter } \\
\text { wheat }\end{array}$ & $\begin{array}{c}\text { Stubble of winter } \\
\text { barley }\end{array}$ & Bare fallow \\
\hline $\begin{array}{l}\text { The number of fractions of soil } \\
\text { with size of less than 50 mm,\% }\end{array}$ & 87.3 & 88.4 & 94.8 \\
\hline Ridgeness, cm & $7.4-7.9$ & $7.1-7.8$ & $6.9-7.2$ \\
\hline $\begin{array}{l}\text { Preservation of plant and crop } \\
\text { residues, \% }\end{array}$ & 65 & 76 & - \\
\hline $\begin{array}{l}\text { Change in the content of } \\
\text { erosion-hazardous particles in } \\
\text { the surface soil layer,\% }\end{array}$ & reduced by 14.0 & reduced by 11.3 & reduced by 5.5 \\
\hline $\begin{array}{l}\text { Depth of tillage, cm } \\
\text { (actual / target) }\end{array}$ & $26.0 / 25$ & $25.5 / 25$ & $28.1 / 25$ \\
& $31.4 / 30$ & $29.9 / 30$ & $31.4 / 30$ \\
$34.5 / 35$ & $34.8 / 35$ & $37.1 / 35$ \\
\hline
\end{tabular}

There is compliance with the agrotechnical requirements of the operating device with polymeric materials, the preservation of plant and crop residues of $65-76 \%$, ridgeness of 6.9-7.9 $\mathrm{cm}$, the quality of crumbling of $87.4-94.8 \%$ with fractions of less than $50 \mathrm{~mm}$ in size. It ensures the fulfillment of the specified depth of soil cultivation $(25-35 \mathrm{~cm})$ by operating device with polymeric materials with allowable deviation (up to $10 \%$ ).

The deformation of a plane-cutting ripper made of polymeric material was observed in a shape close to the cuvilinear path of the sliding surfaces (the path of least resistance) of the soil particles during crumbling of the formation. From the foregoing, the conclusion follows about the advisability of giving a curved shape to plane-cutting ripper when finalizing the operating device [14]. In addition, it is necessary to improve the mounting to the rack of the cultivator in order to strengthen the design and increase the operational reliability of the operating device.

It has been found that polymeric coating held on a metal base by adhesion forces has a limited ability to deform. As a result, the allowable specific loads on it can exceed the 
strength of the coating itself. In this case, special attention should be paid to compliance with the process regimes of applying polymeric material on the metal surface of the operating device. The strength of the adhesive joint depends on the temperature of heating and thermostating, as well as the duration of the cooling, which is determined by the metal content of the part of the operating device. So with an increase in the heating temperature, the strength of the adhesive compound "polymeric material-metal" increases. From physical point of view, this is explained by the fact that polymer degradation processes are amplified, as a result of which molecular chain breaks occur, accompanied by the appearance of polar groups that ensure the formation of adhesive bonds. The introduction of reinforcing elements can significantly increase their mechanical strength and wear resistance, however, internal stresses can occur, leading to deformation and cracks on the surface of the operating device, as well as certain difficulties arise in connection with the use of molding compaction method, namely, compliance with the elongated mode. However, it is very difficult to maintain the accuracy of the maintained modes, especially in agricultural production [19-20].

As a result of studies, it was revealed that under equal operating conditions, there is decrease in the draught resistance of the operating device with polymeric materials to $18.28 \%$ comparing with the operating device made of steel (Table 2). So, the draught resistance for the operating device with a plane-cutting ripper made of steel was $9.3 \mathrm{kN}$, for the operating device using polymeric materials was $7.6 \mathrm{kN}$ [21-22].

Table 2. Comparison results of traction resistance of a new working body with and without polymeric materials.

\begin{tabular}{|l|c|c|}
\hline \multirow{2}{*}{ Name of indicator } & \multicolumn{2}{|c|}{ The value of the indicator for operating device } \\
\cline { 2 - 3 } & with polymeric materials & without polymeric materials \\
\hline $\begin{array}{l}\text { Traction resistance, } \\
\mathrm{kN}\end{array}$ & 7.6 & 9.3 \\
\hline $\begin{array}{l}\text { Decrease in traction } \\
\text { resistance, \% }\end{array}$ & 18.28 & - \\
\hline
\end{tabular}

The use of new operating device with polymeric materials will reduce energy costs by $15-20 \%$, operating costs by $10-21 \%$ [15] and improve the quality of tillage.

\section{Conclusion}

Polymeric materials are advised to be used in the construction of operating devices for energy-saving soil cultivation. Ultra-high molecular polyethylene of low-density was installed on the chisel and clod crusher of the tillage operating device, the thrust plate and the ripper for surface tillage are made entirely of polymeric material. Decrease to $18.28 \%$ of draught resistance of the operating device with polymeric materials was established. There is compliance with the agrotechnical requirements of the operating device with polymeric materials, the preservation of plant and crop residues of $65-76 \%$, ridgeness of 6.9-7.9 $\mathrm{cm}$, the quality of crumbling of $87.4-94.8 \%$ with fractions of less than $50 \mathrm{~mm}$ in size. It ensures the fulfillment of the specified depth of soil cultivation $(25-35 \mathrm{~cm})$ by a operating device with polymeric materials with allowable deviation (up to $10 \%$ ). New operating device with polymeric materials for anti-erosion tillage is advisable to be used. The applicationof a new operating device will reduce energy costs by $15-20 \%$, and operating costs by $10-21 \%$ [16-18]. 


\section{References}

1. I.R. Antypas, A.G. Dyachenko, Engineering Technologies and Systems 3(28), 366-378 (2018) https://doi.org/10.15507/0236-2910.028.201803.366-378

2. S. Heyden, B. Li, K. Weinberg, S. Conti, M. Ortiz, Journal of the Mechanics and Physics of Solids 74, 175-195 (2015) https://doi.org/10.1016/j.jmps.2014.08.005

3. A. Wineman, Mathematics and Mechanics of Solids 14(3), 300-366 (2009) https://doi.org/10.1177/1081286509103660

4. B. Talamini, Y. Mao, L. Anand, Journal of the Mechanics and Physics of Solids 111, 434-457 (2018) https://doi.org/10.1016/j.jmps.2017.11.013

5. Y. Mao, L. Anand, Journal of the Mechanics and Physics of Solids 115, 30-53 (2018) https://doi.org/10.1016/j.jmps.2018.02.008

6. Y. Mao, B. Talamini, L. Anand, Journal of the Mechanics and Physics of Solids 13, 17-24 (2017) http://dx.doi.org/10.1016/j.eml.2017.01.003

7. I. Saprunov, M. Gergesova, I. Emri, Mechanics of Time-Dependent Materials 18(2), 349-372 (2014) https://doi.org/10.1007/s11043-013-9231-3

8. A.R. Shahani, H. Shooshtar, A. Karbasian, Proceedings of the Institution of Mechanical Engineers, Part C: Journal of Mechanical Engineering Science (2018) https://doi.org/10.1177/0954406218802599

9. K. Vemaganti, S. Madireddy, S. Kedari, Mechanics of Time-Dependent Materials, 124 (2019) https://doi.org/10.1007/s11043-018-09403-y.

10. S.G. Parkhomenko, Modeling of the wheeled tractor operation with a cultivator (Interagromash, Rostov-on-Don, 2019) https://doi.10.23947/interagro.2019.6.262-266

11. S.G. Parkhomenko, Modeling of the grain crushers downloading process (Interagromash, Rostov-on-Don, 2019) https://doi.10.23947/interagro.2019.6.267-271

12. G.G. Parkhomenko, Tractors and Agricultural Machinery 6, 32-39 (2018) https://doi.10.31992/0321-4443-2018-6-32-39

13. G.G. Parkhomenko, Tractors and Agricultural Machinery 2, 27-34 (2019) https://doi.10.31992/0321-4443-2019-2-27-34

14. G.G. Parkhomenko, I.V. Bozhko, S.I. Kambulov, The curved shape of working bodies for soil tillage (Interagromash, Rostov-on-Don, 2019) https://doi.10.23947/interagro.2019.6.381-385

15. I.V. Bozhko, G.G. Parkhomenko, Efficiency of application of technical means with new working bodies for implementation of the technological process layer-by-layer subsurface tillage (Interagromash, Rostov-on-Don, 2019) https://doi.10.23947/interagro.2019.6.221-224

16. S.I. Kambulov, I.V. Bozhko, A.V. Olshevskaya, MATEC Web of Conferences 224, 05022 (2018) https://doi.org/10.1051/matecconf/201822405022

17. B. Meskhi, B. Golev, V. Efros, D. Rudoy, A. Olshevskaya, V. Zhurba, Y. Chayka, E3S Web of Conferences 135, 01083 (2019) https://doi.org/10.1051/e3sconf/201913501083

18. G. Parkhomenko, S. Kambulov, A. Olshevskaya, A. Babadzhanyan, N. Gucheva, I. Mekhantseva, IOP Conf. Series: Earth and Environmental Science 403, 012144 (2019) doi:10.1088/1755-1315/403/1/012144

19. V. Zhurba, Y. Chayka, N. Gucheva, D. Ushakov, N. Ugrekhelidze, N. Kulikova, M. Egyan, E3S Web of Conferences 135, $01087 \quad$ (2019) https://doi.org/10.1051/e3sconf/201913501087 
20. V.V. Ivanov, N.P. Pogorelov, N.S. Dontsov, Y.N. Denisenko, (DTS-2019): AIP Conference Proceedings 2188, 020005 (2019) doi.org/10.1063/1.5138379

21. A.A. Korotky, E.V. Marchenko, V.V. Ivanov, S.I. Popov, Ju.V. Marchenko, N.S. Dontsov, INTERAGROMASH 2019: IOP Conference Series: Earth and Environmental Science 403 (2019) doi:10.1088/1755-1315/403/1/012116

22. V.V. Ivanov, N.S. Dontsov, A.V. Kirichek, Key Engineering Materials 736, 105-109 (2017) DOI: 10.4028/ www.scientific.net/ KEM.736.105 